\title{
Dielectric Relaxation Spectroscopy in Synthetic Rubber Polymers: Nitrile Butadiene Rubber and Ethylene Propylene Diene Monomer
}

\author{
Young Il Moon $\mathbb{D}^{1},{ }^{1}$ Jae Kap Jung $\mathbb{D}^{2}{ }^{2}$ and Ki Soo Chung ${ }^{1}$ \\ ${ }^{1}$ Department of Physics and Research Institute of Natural Science, Gyeongsang National University, Jinju 52828, \\ Republic of Korea \\ ${ }^{2}$ Center for Materials and Energy Measurement, Korea Research Institute of Standards and Science, Daejeon 34113, \\ Republic of Korea \\ Correspondence should be addressed to Jae Kap Jung; jkjung@kriss.re.kr
}

Received 29 March 2020; Revised 30 April 2020; Accepted 4 May 2020; Published 28 May 2020

Academic Editor: Marinos Pitsikalis

Copyright ( $\odot 2020$ Young Il Moon et al. This is an open access article distributed under the Creative Commons Attribution License, which permits unrestricted use, distribution, and reproduction in any medium, provided the original work is properly cited.

\begin{abstract}
The dielectric permittivity of synthetic rubber polymers, nitrile butadiene rubber (NBR) and ethylene propylene diene monomer (EPDM), with both frequency and temperature variations, was thoroughly investigated by dielectric relaxation spectroscopy (DRS). The spectrum versus frequency of DRS was analyzed with the semiempirical Havriliak-Negami formula and conductivity contribution by employing the newly developed "dispersion analyzer" analysis program. The main dielectric relaxations called the $\alpha$ - and $\beta$-processes, associated with the cooperative motion of chains in polymers, were discovered in the low-temperature region. In the high-temperature region, we found Maxwell-Wagner-Sillars (MWS) relaxation associated with polymer interfacing and normal-mode $\left(\alpha^{\prime}\right)$ relaxation responsible for end-to-end dipole vector motion. The activation energies of schematic molecular chains responsible for the relaxation processes were obtained with the information about its motional mode. The glass transition temperature and dipole moment for the side group were also determined and compared with those from previous studies. In the EPDM specimen, the peaks of $\alpha$ - and $\beta$-relaxation merged at high temperature and were separated with decreasing temperature. The first observations of both merging and splitting were consistent with the results on the temperature dependency of the relaxation strength. Both contour mapping and three-dimensional plots for the two rubbers provide visual information for the distribution and mapping of relaxation.
\end{abstract}

\section{Introduction}

Many prior studies have been conducted by using various microscopic techniques to investigate the molecular dynamics or chain motions of synthetic rubber polymers [1-5]. One of the most appropriate tools for characterizing the microscopic behavior of polymer systems is dielectric relaxation spectroscopy (DRS) [6-8]. DRS is very sensitive to polymer chain motion attributed to primary and secondary relaxation processes, called $\alpha-, \beta$, , and $\gamma$-relaxation, respectively. Furthermore, the Maxwell-Wagner-Sillars (MWS) relaxation phenomena, which are the signals of the interfacial polarization process of heterogeneous polymers, are only detected through DRS [9-11].

Thus, by employing DRS, we have intensively investigated the molecular dynamics and entire relaxation processes embedded in two kinds of rubber polymers: nitrile butadiene rubber (NBR) and ethylene propylene diene monomer (EPDM), which are used as sealing materials for the fuel container in vehicles and other rubber applications.

By measuring the dielectric permittivity with variations in temperature and frequency, we can obtain the following four important physical properties of a polymer:

(i) The origin of the relaxation phenomenon embedded in the polymer can be determined by analyzing the dielectric spectrum versus frequency and temperature $[12,13]$

(ii) The Arrhenius temperature dependency for the secondary relaxation rate gives the activation energy for the motion of the corresponding molecular chain [14-16] 
(iii) The glass transition temperature can be obtained by fitting the Vogel-Fulcher-Tammann-Hesse (VFTH) formula to the primary relaxation rate [14-16]

(iv) The effective dipole moment for the side group can be obtained by the theories of Onsager and Kirkwood [14-16]

There are a few previous studies on relaxation in synthetic rubber polymers studied here. For instance, the study on the NBR rubber conducted by Psarras et al. [6] incorrectly designated the origin of the specific relaxation spectrum. Similarly, although Xu et al. [8] and Chailan et al. [17] conducted DRS studies on EPDM and fluoroelastomer (FKM) rubbers, their results did not include the relaxation origin, calculation of activation energy, and glass to polymer transition temperatures. In addition, previous works for NBR and EPDM were not undertaken to determine the electric dipole moment of the corresponding molecular structure in polymer chains $[6-8,17-20]$. Thus, the four main physical properties of DRS in these rubbers were not entirely covered and intensively investigated by other researchers.

We designated the effective dipole moment for the common molecular structure. However, due to the effect of the interaction between the dipole and other polar chains in polymer chains, there is a very complicated configuration to calculate the dipole moments for the polymer. Debye tried to calculate the dipole moment using the Boltzman distribution and the relationship between polarizability and permittivity [14-16]. Onsager and Kirkwood modified the Debye theory. Thus, we can commonly obtain a dipole moment for polymers from dielectric measurements $[14,16]$ with the application of modified theories.

In a polymeric rubber system, the measured spectra exhibit an obvious distribution of relaxation time and broadened, superimposed, individual dielectric relaxation spectra. Furthermore, because the relaxation processes that occur on a very long time scale are merged in some temperature regions, deconvolution for complete characterization is difficult to achieve. To analyze the measured data, we developed the analysis program "dispersion analyzer." With the help of this program, we could deconvolute the superimposed dielectric spectra, finding the origin of the entire relaxation phenomenon for a synthetic polymer for the first time. The molecular chains responsible for the relaxation processes were also obtained with information about its motional mode. The activation energy, glass transition temperature, and electric dipole moment for the corresponding molecular chain were determined. Crossover peaks for $\alpha$ - and $\beta$-relaxation in the two polymers were observed. The first observation was consistent with the results on the temperature dependency of the relaxation strength. For visualization, the permittivity data for various temperatures and frequencies are shown as three-dimensional (3D) and contour plots for the three polymers. Thus, we could distinguish the distribution and mapping for relaxation processes.

\section{Materials and Methods}

2.1. Rubber. All rubbers were provided by "KRAIBYRG Rubber" a domestic Korean company.

NBR (Figure 1) is a butadiene-based synthetic rubber made by copolymerizing various combinations of butadiene $\left(\mathrm{CH}_{2} \mathrm{CH}=\mathrm{CHCH}_{2}\right)$ and acrylonitrile $\left(\mathrm{CH}_{2} \mathrm{CHCN}\right)$. The compositions of the NBR rubber are represented in Table 1. To visualize the carbon black filler, the SEM images of the filler-filled NBR rubber are shown in Figure 2.

EPDM (Figure 3) is an ethylene-based synthetic rubber made by copolymerizing various combinations of ethylene $\left(\mathrm{CH}_{2} \mathrm{CH}_{2}\right)$, propylene $\left(\mathrm{CH}_{2} \mathrm{CHCH}_{3}\right)$, and ENB monomer. The chemical composition is shown in Table 2. To visualize the filling agent, the SEM (scanning electron microscope) images of the carbon black filler-filled NBR and EPDM rubbers are shown in Figure 2. The red circles in Figure 2 indicate the aggregate form of the carbon black fillers.

2.2. Dielectric Relaxation Spectroscopy. The measurements of dielectric permittivity were carried out using a VSP-300 (Bio Logics) [21] instrument with a temperature controller. Before starting the measurement, in order to eliminate the effects of the moisture and outgassing, the heat treatment process for all specimens must be done. The heat treatment of all specimens was performed at $85^{\circ} \mathrm{C}$ for 24 hours, which condition was recommended by the CSA Group [22]. The frequency range was set from $0.01 \mathrm{~Hz}$ to $3 \mathrm{MHz}$ for each specific temperature. By applying $1000 \mathrm{mV}$ AC voltage to the specimen, the current was measured, and then, the impedance was obtained. The measurements were performed automatically by a measurement program in the temperature range from $-40^{\circ} \mathrm{C}$ to $100^{\circ} \mathrm{C}$. The dielectric measurement was performed with the cylinder-shaped specimens which has a diameter of $50 \mathrm{~mm}$ and thickness of $2.4 \mathrm{~mm}$. The weight for NBR and EPDM is $5.88 \mathrm{~g}$ and $5.60 \mathrm{~g}$, respectively.

Both the real and imaginary permittivity from the measurements using the VSP-300 frequency response analyzer were calculated from the following relations:

$$
\begin{aligned}
& \varepsilon^{\prime}=\frac{d}{\omega \varepsilon_{0} A} \frac{Z^{\prime \prime}}{\left(Z^{\prime 2}+Z^{\prime \prime 2}\right)}, \\
& \varepsilon^{\prime \prime}=\frac{d}{\omega \varepsilon_{0} A} \frac{Z^{\prime}}{\left(Z^{\prime 2}+Z^{\prime \prime 2}\right)},
\end{aligned}
$$

where impedance $Z=Z^{\prime}-j Z^{\prime \prime} . Z^{\prime}$ and $Z^{\prime \prime}$ are the real and imaginary impedances, respectively. The schematic of the dielectric spectroscopy system is shown in Figure 4.

2.3. Differential Scanning Calorimetry. The differential scanning calorimetry (DSC) measurements of the dynamic glass transition temperature were carried out using Q-600 (TA Instruments) [23]. The measurements were performed with a heating rate of $1^{\circ} \mathrm{C} / \mathrm{min}$ in the temperature range from $-80^{\circ} \mathrm{C}$ to $80^{\circ} \mathrm{C}$. The DSC measurement was conducted with the small granulated-type rubbers which weighs about $8 \mathrm{mg}$ to $10 \mathrm{mg}$. 


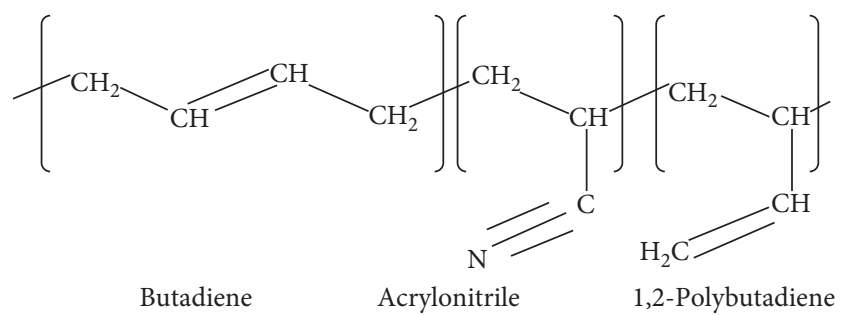

FIgURE 1: Molecular structure of NBR.

TABLE 1: The chemical composition of the NBR rubber compound.

\begin{tabular}{lcc}
\hline Chemical name & Function & $(\%)$ \\
\hline Acrylonitrile-butadiene rubber & Polymer & 40.0 \\
Carbon black & Filler reinforcing & 50.0 \\
1,2-Benzenedicarboxylic acid & Processing aid & 6.0 \\
2-Benzimidazolethiol & Antioxidant & 2.0 \\
Sulfur & Curing agent & 2.0 \\
& & 100.0 \\
\hline
\end{tabular}

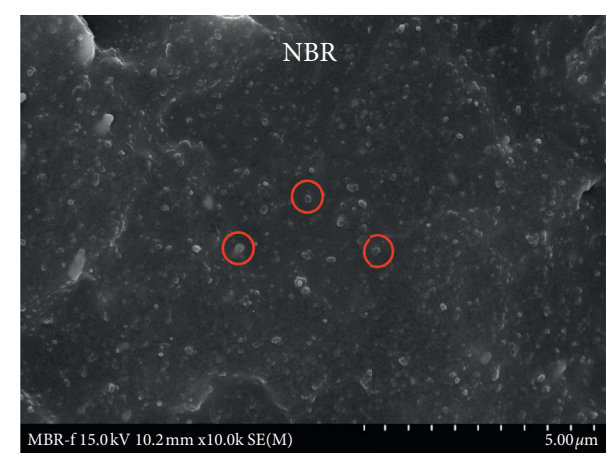

(a)

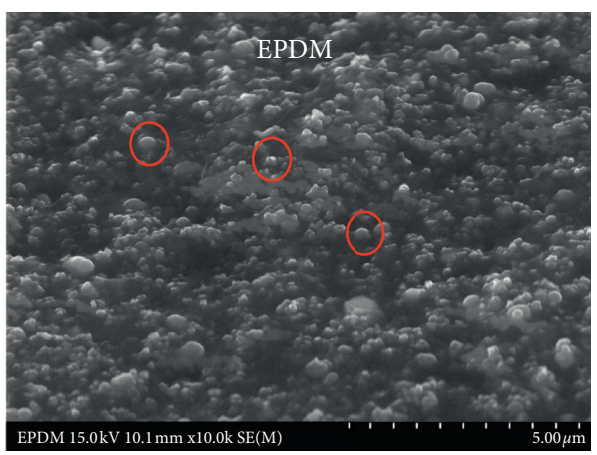

(b)

FIgURE 2: The SEM image of NBR and EPDM rubber. (a) The image of a carbon black filler in the NBR rubber and (b) a carbon black filler in the EPDM rubber. The scale bar of both figures indicated is $5 \mu \mathrm{m}$. The red circles in both figures indicated the aggregate form of the carbon black filler.

\section{Formula for Analyzing Complex Dielectric Permittivity and Relaxation Processes}

To understand the dynamics of the relaxation process in polymers, the experimental complex dielectric permittivity $\varepsilon^{*}(\omega)$ data could be fitted to the Havriliak-Negami (HN) function. The HN functional formalism can be phenomenologically described as a combination of the conductivity term with the HN functional form [24-27] as follows:

$$
\varepsilon^{*}(\omega)=-i \frac{\sigma_{d c}}{\varepsilon_{0} \omega^{s}}+\varepsilon_{\infty}+\sum_{k=1,2, \ldots} \frac{\Delta \varepsilon_{k}}{\left[1+\left(i \omega \tau_{H N k}\right)^{1-a_{k}}\right]^{b_{k}}},
$$

where the first term $\sigma_{\mathrm{dc}} / \varepsilon_{0} \omega^{s}$ accounts for the DC conductivity of the samples and electrode polarization effect; its contribution is dominant at the highest temperature and the lowest frequency considered in the study; $\sigma_{\mathrm{dc}}$ is the DC conductivity; $\varepsilon_{0}$ is the vacuum permittivity of $8.854 \times 10^{-12} \mathrm{~F} / \mathrm{m} ; s$ is the included ionic charge carrier which causes electrode or Maxwell-Wagner Polarization effects; in practice, often $\varepsilon^{\prime \prime} \sim \omega^{-s}$ with $s<1$; the summation symbol in the last term indicates the occurrence of more than one relaxation process; $\tau_{H N k}$ is the characteristic average relaxation time of process $k$; the exponents $a_{k}$ and $b_{k}\left(\left(0 \leq a_{k} \leq 1, b_{k} \leq 1\right)\right.$ are the HN-shape parameters describing the distribution of the relaxation times; the values of $\alpha_{k}$ and $\beta_{k}$ are related to the linewidth and asymmetry relaxation loss peak, respectively; the dielectric relaxation strength $\varepsilon_{s}-\varepsilon_{\infty}$ is represented as $\Delta \varepsilon_{k}$.

To deconvolute the complex dielectric spectra, we employed the "dispersion analyzer" which was developed by us.

A secondary relaxation due to isolated molecules or impurities may also be present, showing comparably higher relaxation rates [23]. The activation energies of secondary relaxations for $\alpha^{\prime}-, \beta$-, and $\gamma$-relaxations were determined by assuming the Arrhenius temperature dependence:

$$
f_{p, \beta}=f_{\infty, \beta} \exp \left[-\frac{E_{a}}{k T}\right] \text {, }
$$

where $f_{p, \beta}$ is the position of the center peak for the secondary relaxation rate, $f_{\infty, \beta}$ is the pre-exponential factor, and $E_{a}$ is the activation energy. The activation energy $E_{a}$, related to the slope of $\log f_{p, \beta}$ versus $1 / T$, depends on both the internal rotation barriers and the environment of a moving unit.

The position $\left(f_{p \alpha}\right)$ of the peak center in the relaxation rate for the $\alpha$-process allows the non-Arrhenius temperature dependence described by the VFTH temperature dependence model:

$$
\ln f_{p \alpha}=\ln f_{p \infty}-\frac{A}{T-T_{0}},
$$

where $f_{p \infty}$ and $A$ are constants and $T_{0}$ is the so-called ideal glass transition or the Vogel temperature [14-16].

\section{Results and Discussion}

4.1. NBR. The 3D frequency and temperature dependence for imaginary parts of permittivity in NBR are shown in Figure 5. The entire five relaxation values, called conductivity, $\alpha, \alpha, \beta$, and $\gamma$, by simulation could be assigned by employing the "dispersion analyzer." The arrows in Figure 5 indicate the evolution of the relaxation peak versus temperature variation.

After deconvolution, the simulation results of the relaxation processes by the dispersion analyzer for five 


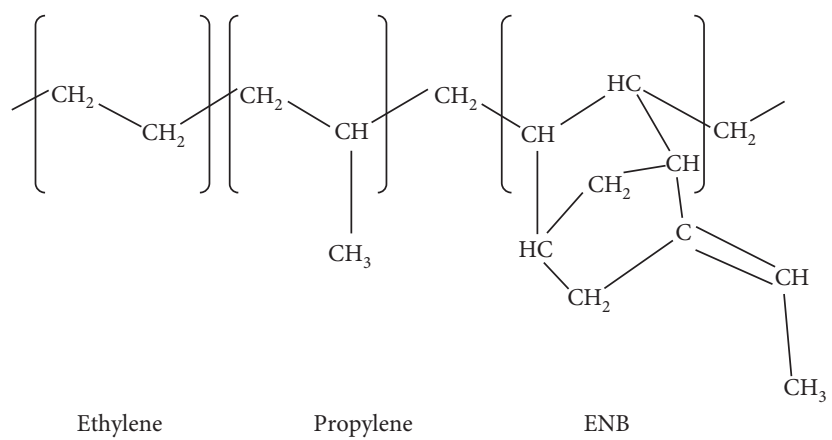

Figure 3: Molecular structure of EPDM.

TABLE 2: The chemical composition of the EPDM rubber compound.

\begin{tabular}{lcc}
\hline Chemical name & Function & $(\%)$ \\
\hline Ethylene propylene rubber & Polymer & 58.0 \\
Carbon black & Filler reinforcing & 34.0 \\
Zinc oxide & Processing aid & 3.0 \\
Dicumyl peroxide & Antioxidant & 5.0 \\
& & 100.0 \\
\hline
\end{tabular}

representative temperatures $\left(-40^{\circ} \mathrm{C},-25^{\circ} \mathrm{C}, 20^{\circ} \mathrm{C}, 50^{\circ} \mathrm{C}\right.$, and $100^{\circ} \mathrm{C}$ ) in the frequency domain are shown in Figure 6. Also, the fitting parameters of each relaxation process are summarized in Table 3.

The $\alpha$ - and $\alpha$-relaxation spectra were well fitted by $\mathrm{HN}$ of equation (2). The $\beta$ - and $\gamma$-relaxation spectra were fitted by the Cole-Cole equation when $\beta=1$ in the HN function because the secondary relaxation has a symmetrical shape [15]. The entire loss spectra for the relaxation process visibly shifted toward lower frequency with decreasing temperature.

The $\alpha$-process is called normal mode relaxation, which is a signal of the fluctuational motion of the end-to-end dipole vector for the polymer chain and only observed in a Stockmayer type A polymer with a dipole moment vector parallel to the backbone chain [28-31]. Since the EPDM has a nonparallel dipole vector with the backbone chain, the $\alpha^{\prime}$-process was only detected in $\mathrm{NBR}$, which has a parallel dipole vector with the backbone chain. Additionally, the $\alpha$-relaxation is responsible for backbone chain motion [32-35], which was also detected in EPDM.

The origins of the $\beta$ - and $\gamma$-relaxations are the orientational motion of the vinyl groups $\left[-\mathrm{C}_{2} \mathrm{H}_{3}\right]$ and cyano groups [-CN], respectively. The $\gamma$-relaxation, of even smaller molecular parts (cyano groups [-CN]), can often be found at higher frequencies or temperatures below $\beta$-relaxation in isochronal scans $[15,36-38]$. The origins of the corresponding dielectric relaxation for NBR are represented with a schematic molecular chain structure and its motional mode in Figure 7.

The position $\left(f_{0}\right)$ of the center peak for the relaxation rate versus the reciprocal temperature for NBR is shown in Figure 8. As shown in the inset of Figure $8, \Delta \varepsilon$ for $\alpha$-relaxation increases with decreasing temperature. The entire relaxation peaks shifted to the lower frequency with decreasing temperature, which was the same as that seen in Figure 6. The temperature behavior of $\Delta \varepsilon$ is a general trend

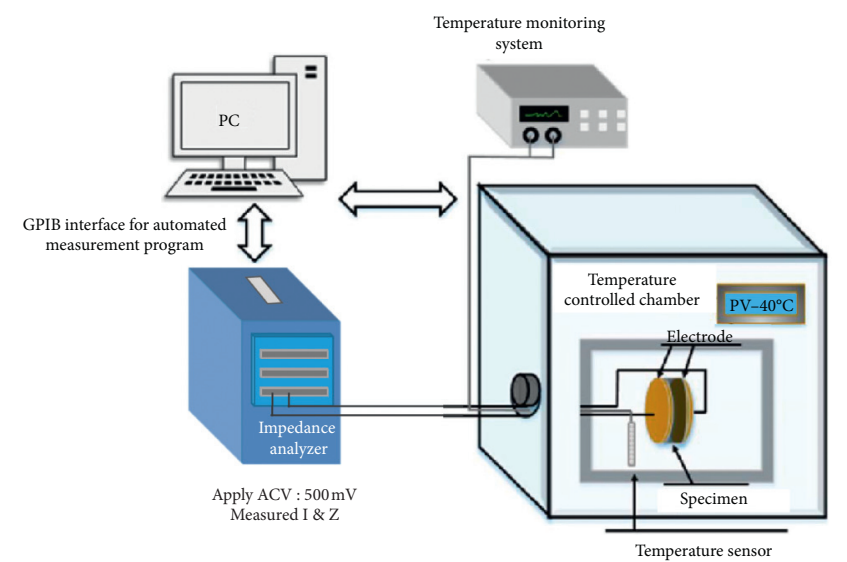

FIgURE 4: Configuration of the automatic impedance spectroscopy system for complex dielectric permittivity measurements versus frequency and temperature.

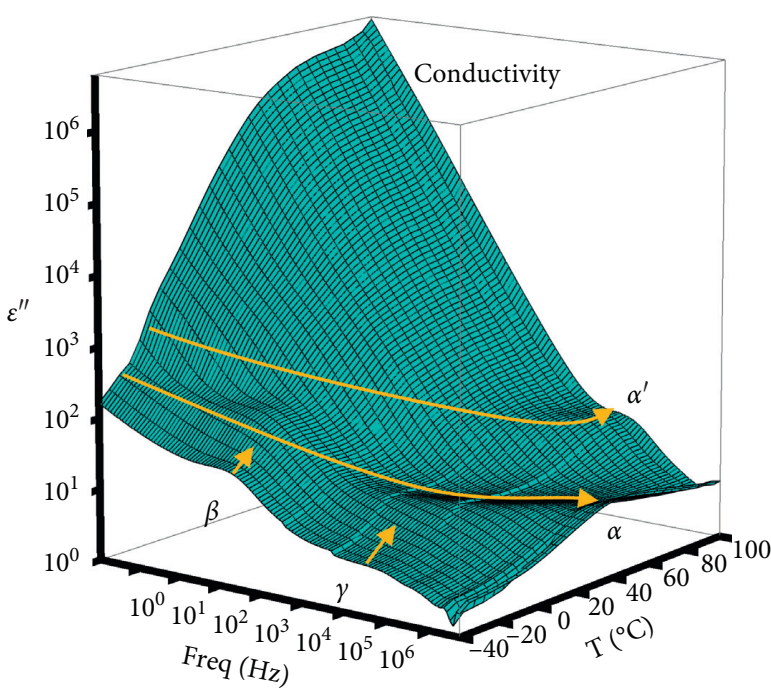

FIGURE 5: 3D plot of the imaginary permittivity for NBR.

for $\alpha$-relaxation. This temperature dependence of $\Delta \varepsilon$ can be predicted and explained by the dipole theory of Kremer and Schönhals [14].

The activation energy for the $\alpha^{\prime}-, \beta$-, and $\gamma$-processes was calculated by the Arrhenius temperature dependence of equation (3). The activation energy for 

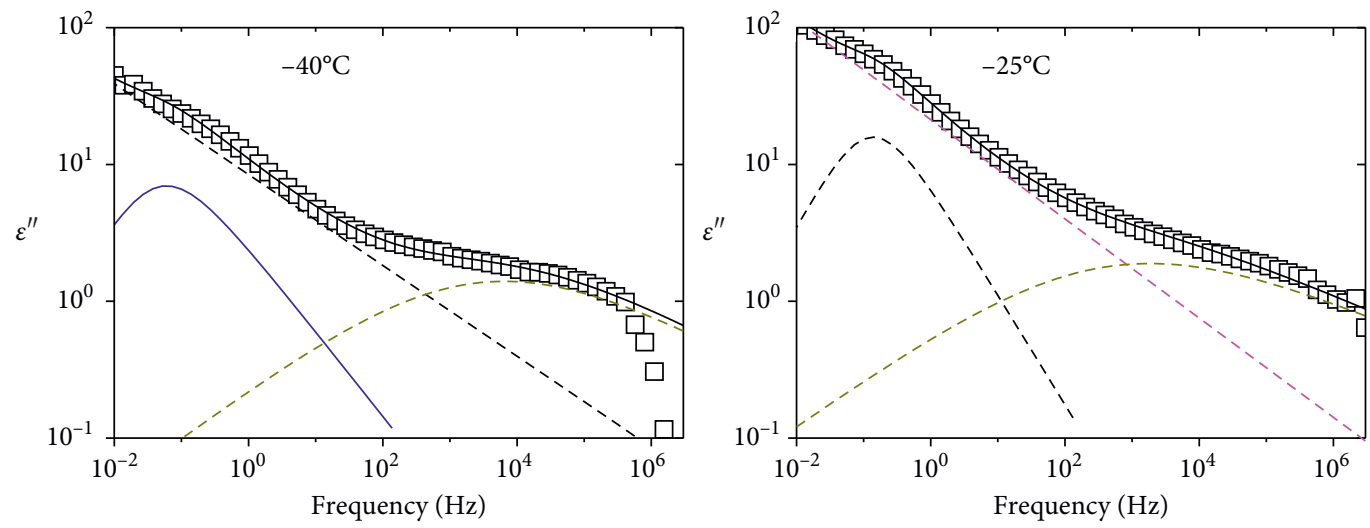

$$
\begin{aligned}
\square \quad \text { Meas. data } & ---\beta \text {-relax. } \\
- \text { Total fit } & ---\gamma \text {-relax. } \\
---\alpha \text {-relax. } &
\end{aligned}
$$

$\square \quad$ Meas. data $\quad---\alpha^{\prime}$-relax.

— Total fit

$--\gamma$-relax.
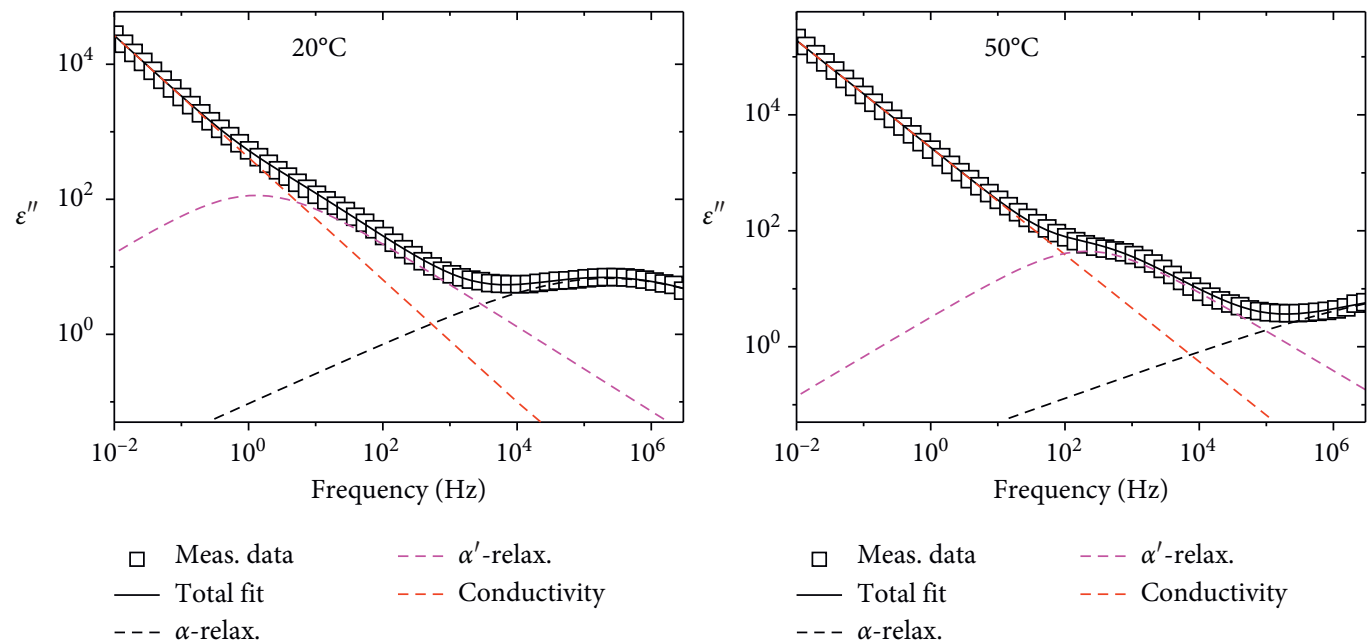

Meas. data

- - - $\alpha^{\prime}$-relax.

- Total fit

- - - Conductivity

- Total fit

--- Conductivity

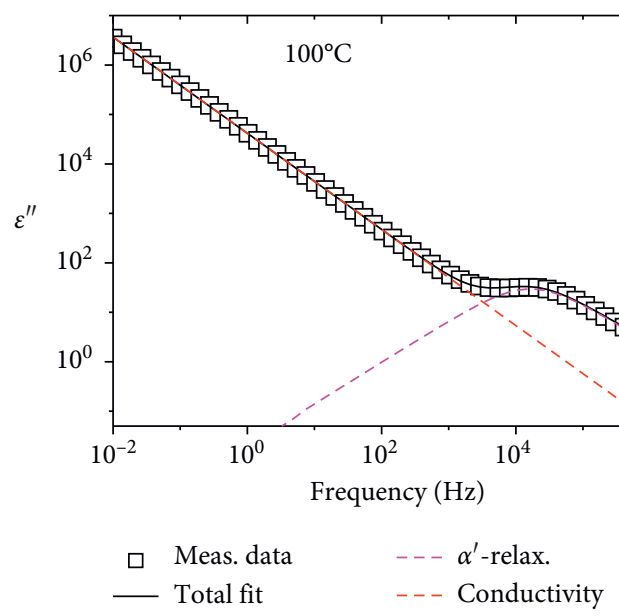

FIGURE 6: Simulation results for five representative temperatures within the range from $-40^{\circ} \mathrm{C}$ to $100^{\circ} \mathrm{C}$. The total fitting results are presented with black solid lines through the data (open square), which are the sum of the black dashed line ( $\alpha$-relaxation), blue dashed line ( $\beta$-relaxation), dark yellow dashed line ( $\gamma$-relaxation), magenta dashed line ( $\alpha^{\prime}$-relaxation), and red dashed line (conductivity).

$\alpha^{\prime}$-relaxation calculated according to equation (3) was found to be $82.7 \mathrm{~kJ} / \mathrm{mol}$. The activation energies for $\gamma$ and $\beta$-relaxations were 10.2 and $22.4 \mathrm{~kJ} / \mathrm{mol}$, respectively.
The results are summarized in Table 4 . The activation energies of the $\beta$ - and $\gamma$-relaxations, which are related to the orientational motion of the vinyl and cyano groups, respectively, were compared with prior results [39]. The $E_{a}$ 
TABLE 3: Fitting parameters of the specific relaxation process.

\begin{tabular}{|c|c|c|c|c|c|c|c|}
\hline$T\left({ }^{\circ} \mathrm{C}\right)$ & Relaxation & $\Delta \varepsilon$ & $f_{0}(\mathrm{~Hz})$ & $a$ & $b$ & $\sigma_{\mathrm{dc}}(\mathrm{s} / \mathrm{m})$ & $s$ \\
\hline \multirow{3}{*}{-40} & $\alpha$ & $3.6 \times 10^{3}$ & $1 \times 10^{-4}$ & 0.16 & 0.4 & - & - \\
\hline & $\beta$ & $2.1 \times 10^{1}$ & $4.4 \times 10^{-2}$ & 0.17 & 0.75 & - & - \\
\hline & $\gamma$ & $1.1 \times 10^{1}$ & $2.7 \times 10^{3}$ & 0.64 & 0.72 & - & - \\
\hline \multirow{3}{*}{-25} & $\alpha$ & $3.9 \times 10^{1}$ & $1.2 \times 10^{-1}$ & 0.11 & 0.89 & - & - \\
\hline & $\alpha^{\prime}$ & $5.8 \times 10^{3}$ & $0.1 \times 10^{-6}$ & 0 & 0.36 & - & - \\
\hline & $\gamma$ & $1.6 \times 10^{1}$ & $4.3 \times 10^{2}$ & 0.65 & 0.6 & - & - \\
\hline \multirow{3}{*}{20} & $\alpha$ & $3.7 \times 10^{1}$ & $2.3 \times 10^{5}$ & 0.55 & 1 & - & - \\
\hline & $\alpha^{\prime}$ & $4.3 \times 10^{2}$ & $1.3 \times 10^{0}$ & 0.37 & 1 & - & - \\
\hline & Conductivity & - & - & - & - & $1.9 \times 10^{-8}$ & 0.91 \\
\hline \multirow{3}{*}{50} & $\alpha$ & $1.5 \times 10^{4}$ & $6.4 \times 10^{6}$ & 0.59 & 0 & - & - \\
\hline & $\alpha^{\prime}$ & $1.5 \times 10^{2}$ & $2.1 \times 10^{2}$ & 0.31 & 1 & - & - \\
\hline & Conductivity & - & - & - & - & $1.3 \times 10^{-7}$ & 0.92 \\
\hline \multirow{2}{*}{100} & $\alpha^{\prime}$ & $3.2 \times 10^{1}$ & $1.4 \times 10^{4}$ & 0.2 & 0.82 & - & - \\
\hline & Conductivity & - & - & - & - & $1.2 \times 10^{-6}$ & 0.99 \\
\hline
\end{tabular}

values are consistent with each other within A-type measurement uncertainty.

The glass transition temperature $T_{g}$ for DRS can be obtained from the temperature dependence of $f_{0}$ for an $\alpha$-relaxation process measured at different frequencies. The $T_{g}$ at DRS is defined as the temperature at which $f_{0}$ of the $\alpha$-relaxation process reaches $1.6 \mathrm{mHz}$, which was empirically defined in many other prior studies, by extrapolating the fitting of equation (4) in Figure 9(a) $[15,40-43] . T_{g}$ for DRS was determined to be $242.1 \mathrm{~K}( \pm 3.2)$, as shown in Figure 9(a), which was compared with the $T_{g}$ determined by DSC measurements (Figure 9(b)), where $T_{g}$ for DSC is usually defined as the half-height of the heat capacity increase $\left((1 / 2) \Delta C_{p}\right.$, also called the "temperature of half-unfreezing") [15]. $T_{g}$ (DSC) obtained was $242.2 \mathrm{~K}$. Compared with two other experimental results, the $T_{g}$ values are consistent with each other.

The dipole moment for each monomer in NBR can be calculated from the dielectric measurement data. We used the Onsager and Kirkwood dipole theory. The Onsager theory was considered as the enhancement of the permanent dipole moment of a molecule $\mu$ by the polarization of the environment. The relaxation strength $(\Delta \varepsilon)$ in the Onsager formula is given by

$$
\Delta \varepsilon=\frac{1}{3 \varepsilon_{0}} F \frac{\mu^{2}}{k_{B} T} \frac{N}{V},
$$

where $\mu$ is the permanent molecular electric dipole moment, $k_{B}$ is the Boltzmann constant, $N$ and $V$ are the number of dipoles in the system and system volume, respectively, and the $F$ value corresponds to the error introduced by neglecting the reaction field. Kirkwood theory considered the effect of dipole-dipole interactions. The Kirkwood formula was given by

$$
\Delta \varepsilon=\frac{1}{3 \varepsilon_{0}} g_{K F} \frac{\mu^{2}}{k_{B} T} \frac{N}{V},
$$

where $g_{K F}$ is the Kirkwood factor considering the effect of dipole-dipole interactions. However, the calculation of $g_{K F}$ for an isolated polymeric chain is more complicated than that for molecules with low mass because carbon atoms with numbers from $10^{4}$ to $10^{6}$ are covalently bound for the isolated polymeric chain [14]. In our case, the two specimens have a complicated constitution and a large bond scale. Thus, Kirkwood theory through the calculation of $g_{K F}$ was not applied. Since our dipole moment calculation was performed on the polymeric system to which various monomers were combined, it was carried out with macroscopic calculation of the dipole chain corresponding to the respective dielectric relaxation process. The calculation results contain some effects on other dipole chains.

In case of the NBR rubber, because $\beta$ - and $\gamma$-peaks were observed at approximately $-40^{\circ} \mathrm{C}$, the calculations for the dipole moment were carried out at this temperature. By applying the epsilon parameters $\left(\Delta \varepsilon, \varepsilon_{s}\right.$. and $\left.\varepsilon_{\infty}\right)$ obtained through the fitting simulations to equation (2), the dipole moments were determined as shown in Table $5 \mu_{\text {Ons }}$ indicates the dipole moment calculated by equation (5). The calculation results were comparable with prior results [44].

The $\alpha$ - and $\alpha^{\prime}$-relaxations were mapped with 2D contours of imaginary permittivity for the relaxation rate versus reciprocal temperature. The mapping results are shown in Figure 10. The $\alpha$-relaxation has a symmetrical spectrum. However, the morphologies of the $\alpha$-relaxation spectra have asymmetric shapes in the frequency domain, as indicated by arrows.

4.2. EPDM. The 3D frequency and temperature dependence for imaginary parts of permittivity for EPDM are shown in Figure 11. The four relaxations called conductivity, MWS, $\alpha$, and $\beta$ were observed. The arrows in Figure 11 indicate the evolution of the relaxation peak versus temperature variation.

The simulation results for five representative temperatures $\left(-40^{\circ} \mathrm{C},-20^{\circ} \mathrm{C}, 20^{\circ} \mathrm{C}, 60^{\circ} \mathrm{C}\right.$, and $\left.100^{\circ} \mathrm{C}\right)$ in the frequency domain are shown in Figure 12. After deconvolution, four relaxation spectra observed at five temperatures were defined as a corresponding relaxation process. The fitting parameters of each relaxation process are also summarized in Table 6. 


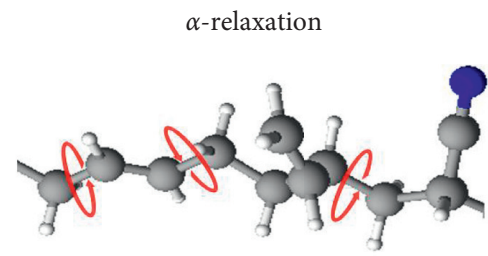

(rotational motion of segmental chain)

$\beta$-relaxation

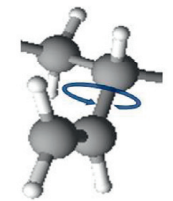

(orientational motion of vinyl-side-groups)

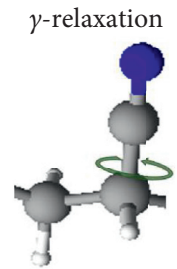

(orientational motion of cyan-side-groups)

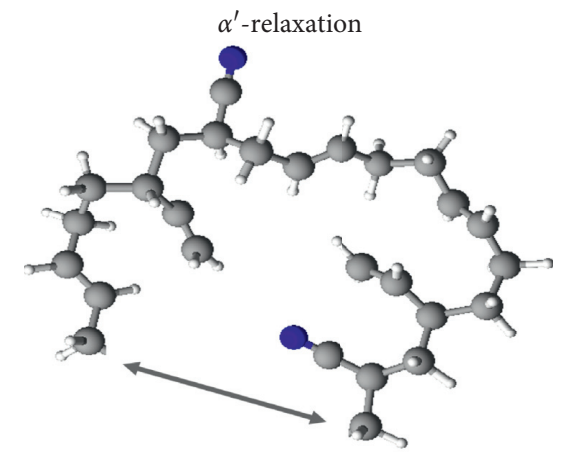

(fluctuational motion of end-to-end dipole vector)

Carbon

Nitrogen

Hydrogen

FIGURE 7: Assignment of the dielectric relaxation process for the schematic molecular chain structure and its motion mode in NBR.

The MWS and $\beta$-relaxation spectra were fitted by the Cole-Cole equation because they have symmetrical shapes. The $\alpha$-relaxation spectrum was fitted by the $\mathrm{HN}$ equation. As the temperature increased, the two separate $\alpha$ - and $\beta$-peaks merged above $290 \mathrm{~K}$. Thus, the loss spectrum above $290 \mathrm{~K}$ was fitted using the superposition of the Cole-Cole and HN equations. When the temperature decreases, the positions of the relaxation peaks of MWS and $\alpha$ shifted significantly toward the low frequency. However, the $\beta$-relaxation peak was less shifted visibly than the other relaxation spectra in the same polymer and in different rubber polymers. This behavior for the $\beta$-process was explained by the relationship between the molecular size and activation energy [15].

The $\alpha$-relaxation originates from the rotation of the segmental chain, and the $\beta$-relaxation originates from the orientation of the methyl group $\left[-\mathrm{CH}_{3}\right]$, which is the side group in the propylene monomer $\left[-\mathrm{C}_{3} \mathrm{H}_{6}\right]$. The MWS relaxation (also called the interfacial relaxation) originates from the polarized process in the interfacial surface of heterogeneous polymers $[9,45,46]$. However, the origin of the unknown peak observed at $-40^{\circ} \mathrm{C}$ is still unclear. The origins of the corresponding dielectric relaxation for EPDM are represented with a schematic molecular chain structure and its motional mode in Figure 13.

The position $\left(f_{0}\right)$ of the center peak for the relaxation rate plot versus the reciprocal temperature for EPDM is shown in Figure 14. The entire loss spectra for the relaxation process were visibly shifted toward lower frequencies with decreasing temperature. $\Delta \varepsilon$ for $\alpha$-relaxation increased with decreasing temperature, whereas $\Delta \varepsilon$ for $\beta$-relaxation 
$\mathrm{T}(\mathrm{K})$

400333286250

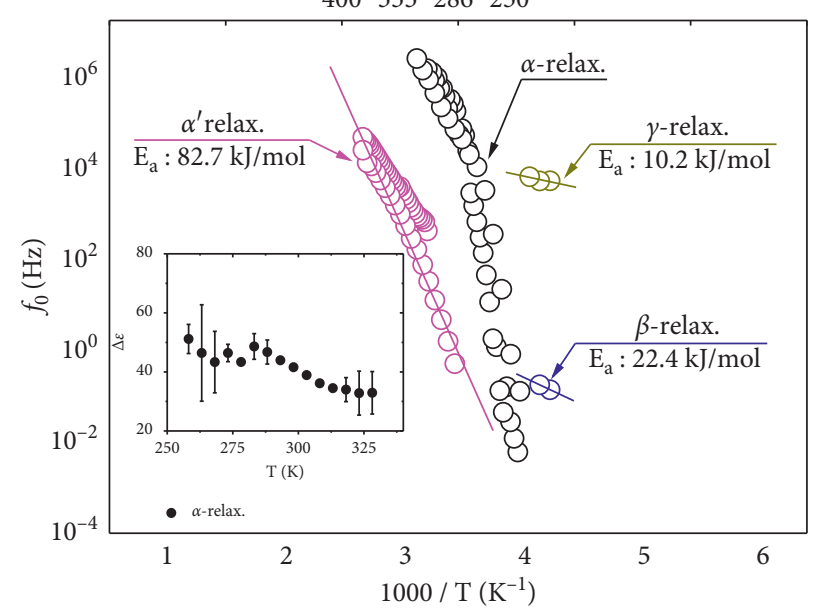

FIGURE 8: The relaxation rate versus reciprocal temperature for NBR. The activation energy for the relaxation process is the slope of the solid line. The overlapped circle symbols of $\alpha$ and $\alpha$ just denote a repeated analysis. The inset shows the variation in the relaxation strength.

TABLE 4: Activation energies and pre-exponential factors for $\alpha^{\prime}-, \beta$-, and $\gamma$-relaxations in NBR.

\begin{tabular}{|c|c|c|c|}
\hline Type of relaxation & $E_{a}(\mathrm{~kJ} / \mathrm{mol})$ & $f_{\infty, \beta}(\mathrm{Hz})$ & $E_{a}$ in previous study [39] $(\mathrm{kJ} / \mathrm{mol})$ \\
\hline $\bar{\alpha}$ & $82.7 \pm 3.4$ & $1.1 \times 10^{16}$ & \\
\hline$\beta$ & $22.4 \pm 3.2$ & $1.2 \times 10^{5}$ & 21.9 \\
\hline$\gamma$ & $10.2 \pm 6.2$ & $6.6 \times 10^{5}$ & 15.5 \\
\hline
\end{tabular}

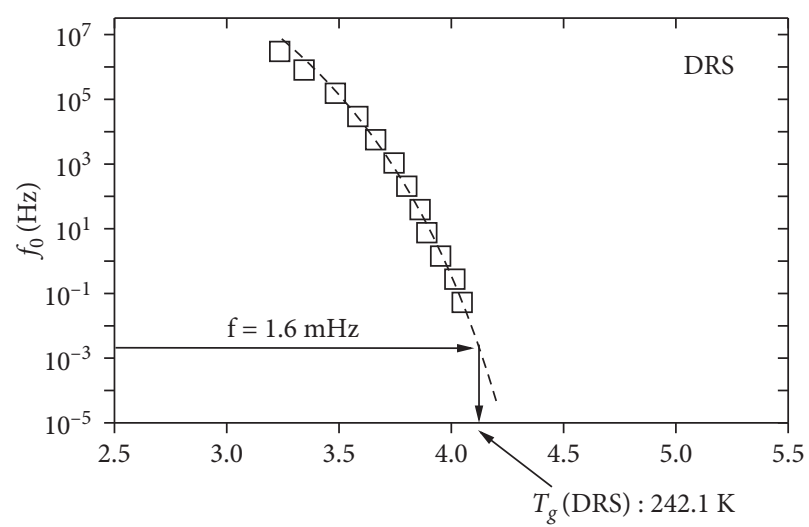

(a)

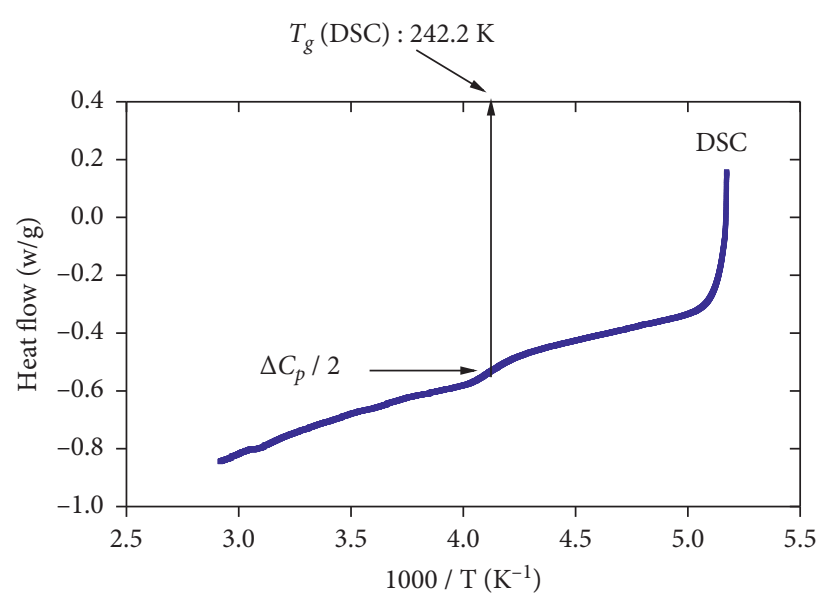

(b)

FIGURE 9: (a) the glass transition temperature determined by DRS and (b) the glass transition temperature determined by DSC.

TABLE 5: The dipole moment calculated for a specific monomer in NBR.

\begin{tabular}{lccc}
\hline Type of relaxation & $T(\mathrm{~K})$ & $\mu_{\text {ons }}(D)$ & $\mu$ in prior result $[44](D)$ \\
\hline$\gamma$ (acrylonitrile) & 235 & 4.7 & 4 \\
$\beta$ (vinyl) & 235 & 4.6 & \\
\hline
\end{tabular}



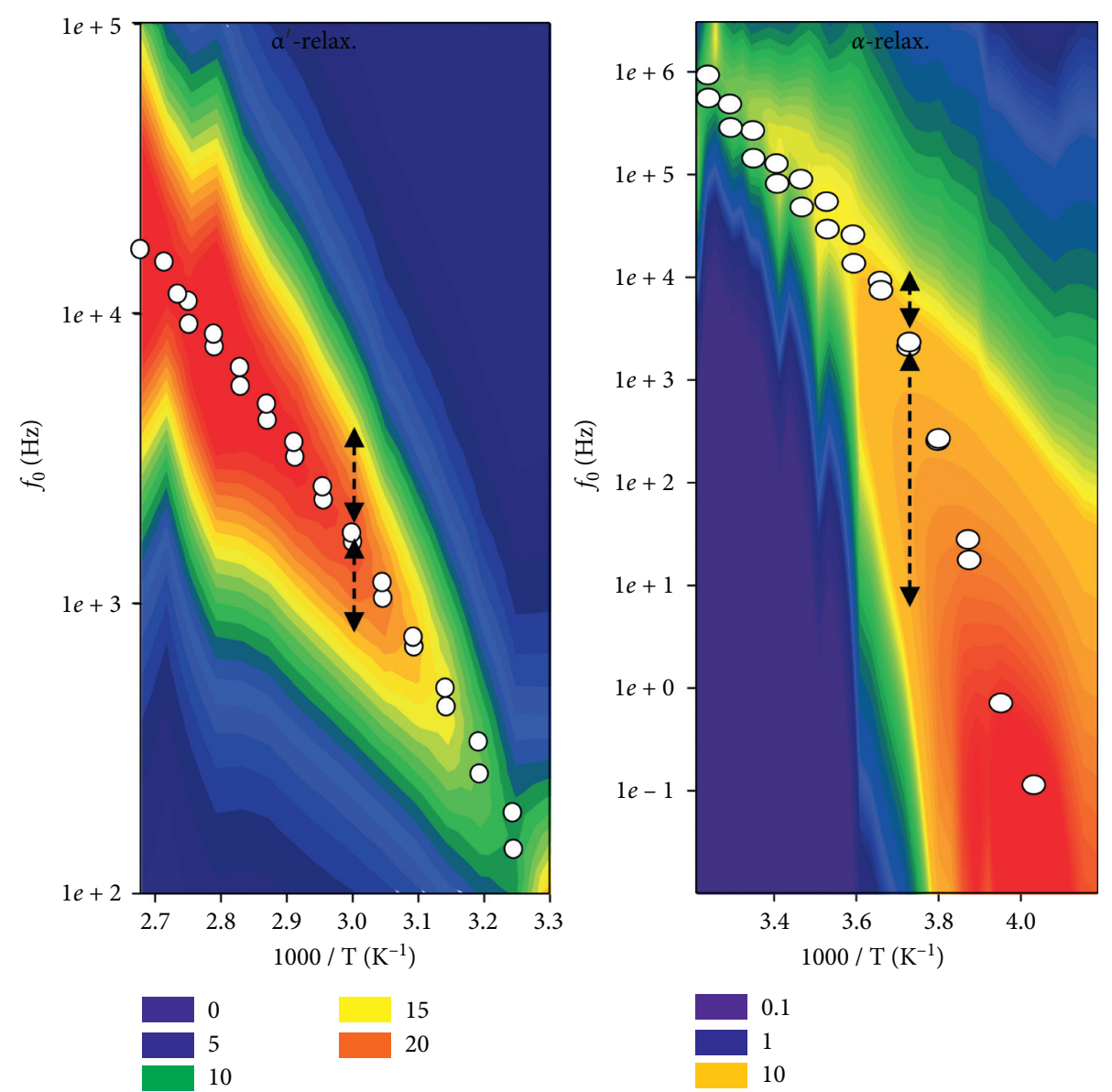

FIGURE 10: Relaxation rate and contour plot of the dielectric relaxation phenomena for NBR. The overlapped circle symbols just denote the repeated analysis.

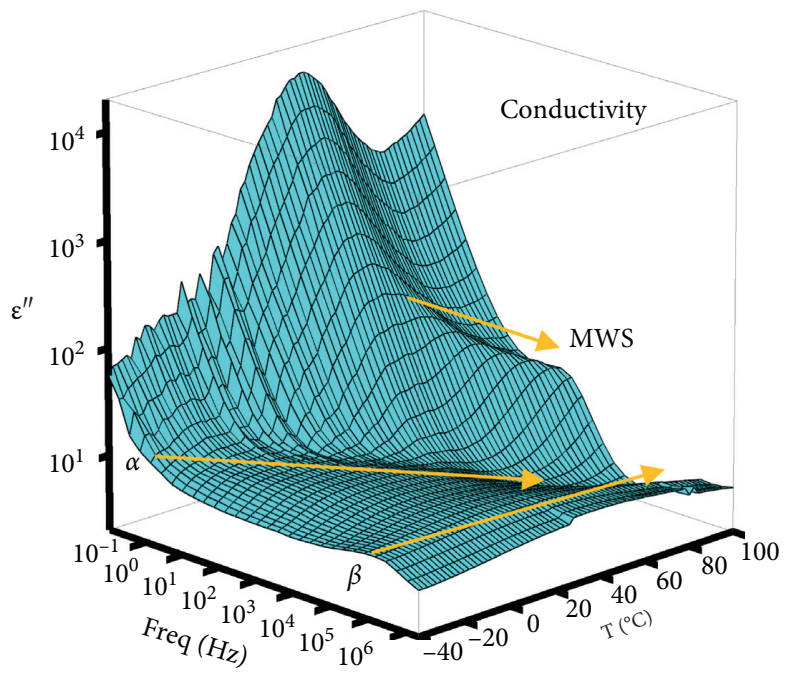

FIGURE 11: 3D plot of the imaginary permittivity for EPDM. 

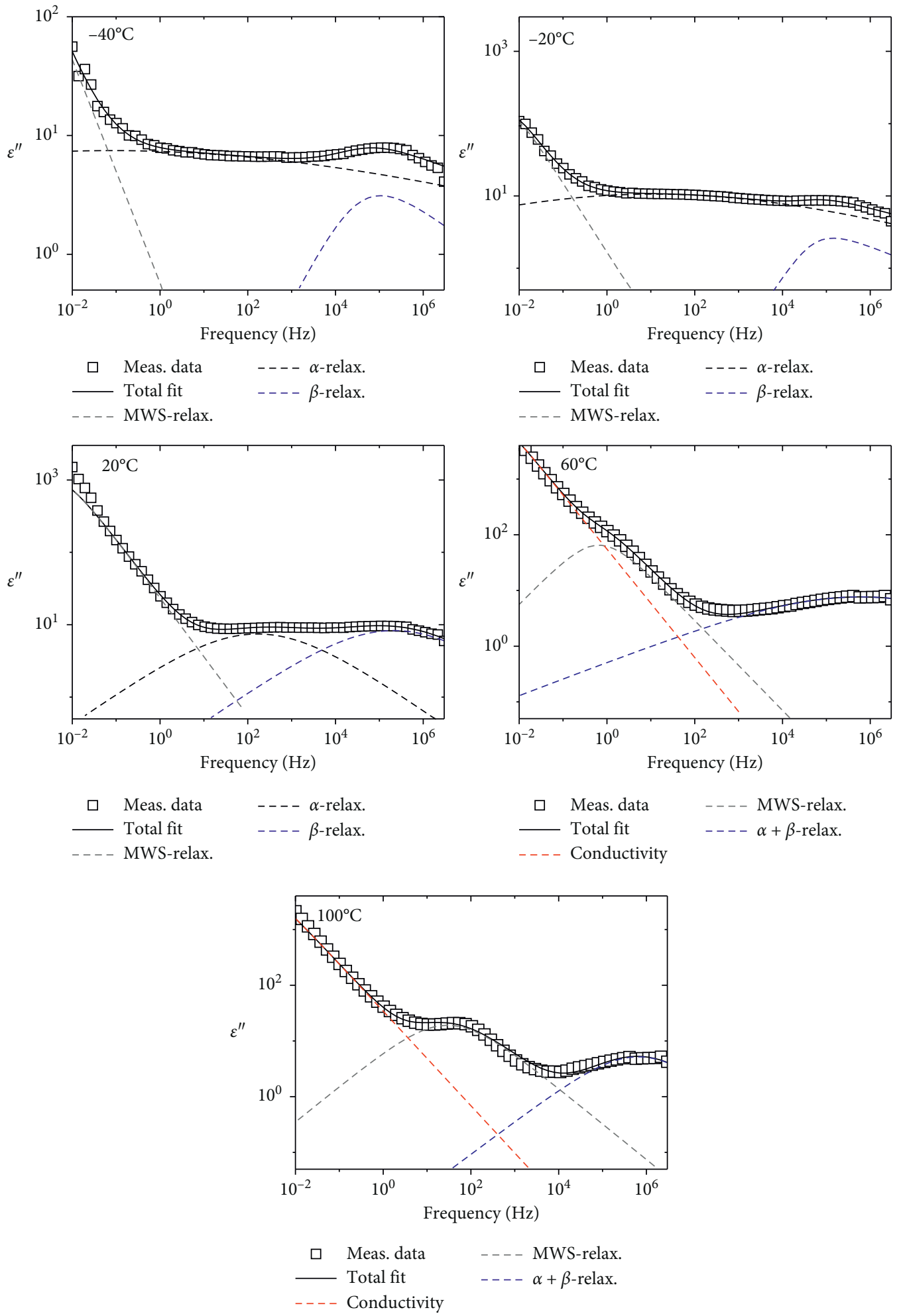

FIGURE 12: Simulation results for five representative temperatures in the range from $-40^{\circ} \mathrm{C}$ to $100^{\circ} \mathrm{C}$. The total fitting results are presented with black solid lines through the data (open square), which are the sum of the black dashed line $(\alpha$-relaxation), blue dashed line ( $\beta$-relaxation), gray dashed line (MWS relaxation), red dashed line (conductivity), and navy dashed line $(\alpha+\beta$-relaxation). 
TABLE 6: Fitting parameters of the specific relaxation process.

\begin{tabular}{|c|c|c|c|c|c|c|c|}
\hline$T\left({ }^{\circ} \mathrm{C}\right)$ & Relaxation & $\Delta \varepsilon$ & $f_{0}(\mathrm{~Hz})$ & $a$ & $b$ & $\sigma_{\mathrm{dc}}(\mathrm{s} / \mathrm{m})$ & $s$ \\
\hline \multirow{3}{*}{-40} & MWS & $4.9 \times 10^{3}$ & $6.7 \times 10^{-5}$ & 0 & 0.94 & - & - \\
\hline & $\alpha$ & $1.9 \times 10^{2}$ & $5.8 \times 10^{-2}$ & 0.89 & 0.96 & - & - \\
\hline & $\beta$ & $1.5 \times 10^{1}$ & $3.3 \times 10^{4}$ & 0.27 & 0.39 & - & - \\
\hline \multirow{3}{*}{-20} & MWS & $2.6 \times 10^{3}$ & $5.2 \times 10^{-3}$ & 0 & 0.95 & - & - \\
\hline & $\alpha$ & $1.6 \times 10^{2}$ & $8.6 \times 10^{0}$ & 0.83 & 0.94 & - & - \\
\hline & $\beta$ & $1.2 \times 10^{1}$ & $4.5 \times 10^{4}$ & 0.07 & 0.27 & - & - \\
\hline \multirow{3}{*}{20} & MWS & $1 \times 10^{4}$ & $1 \times 10^{-3}$ & 0.12 & 1 & - & - \\
\hline & $\alpha$ & $4.3 \times 10^{1}$ & $1.7 \times 10^{2}$ & 0.58 & 1 & - & - \\
\hline & $\beta$ & $4.8 \times 10^{1}$ & $2.1 \times 10^{5}$ & 0.58 & 1 & - & - \\
\hline \multirow{3}{*}{60} & Conductivity & - & - & - & - & $3.1 \times 10^{-9}$ & 0.92 \\
\hline & MWS & $1.3 \times 10^{2}$ & $7.1 \times 10^{-1}$ & 0 & 0.82 & - & - \\
\hline & $\alpha+\beta$ & $8.7 \times 10^{1}$ & $2.6 \times 10^{6}$ & 0.78 & 1 & - & - \\
\hline \multirow{3}{*}{100} & Conductivity & - & - & - & - & $1.6 \times 10^{-9}$ & 0.86 \\
\hline & MWS & $6.1 \times 10^{1}$ & $3.3 \times 10^{1}$ & 0.26 & 1 & - & - \\
\hline & $\alpha+\beta$ & $4.3 \times 10^{1}$ & $6.2 \times 10^{4}$ & 0.41 & 0.21 & & \\
\hline
\end{tabular}

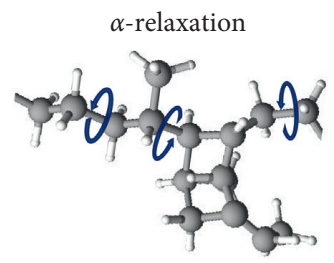

(rotational motion of segmental chain)

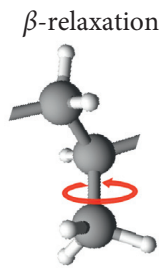

(orientational motion of methyl-side-groups)

Carbon

Hydrogen

FIgURE 13: Assignment of the dielectric relaxation process for the schematic molecular chain structure and its motional mode in EPDM.

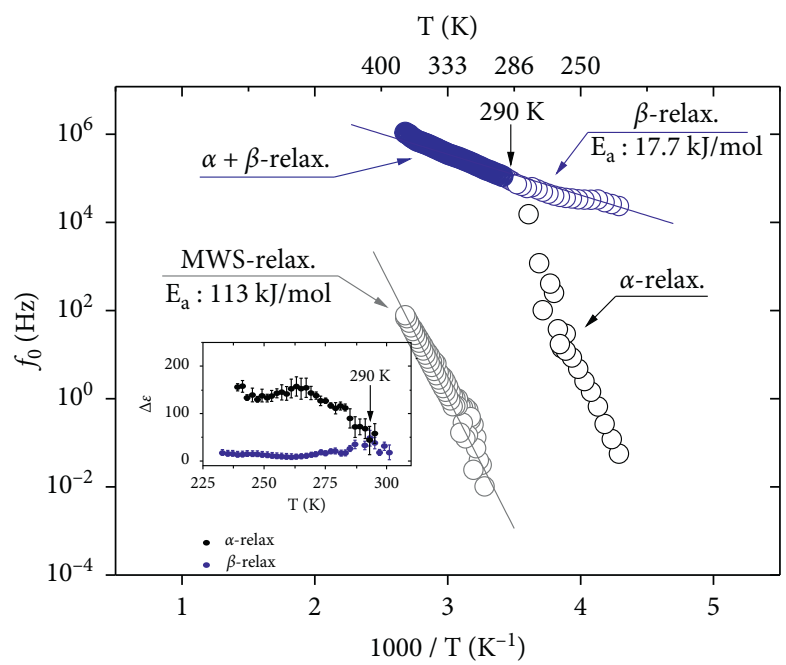

FIgURE 14: The relaxation rate versus reciprocal temperature for EPDM. The activation energy for the relaxation process was the slope of the solid line. The overlapped circle symbols of MWS and $\alpha$-relaxation just denote the repeated analysis. The inset shows the variation in relaxation strength. 
TABLE 7: The activation energy and pre-exponential factor for MWS and $\beta$-relaxations in EPDM.

\begin{tabular}{lccc}
\hline Type of relaxations & $E_{a}(\mathrm{~kJ} / \mathrm{mol})$ & $f_{\infty, \beta}(\mathrm{Hz})$ & $E_{a}$ in prior result [39] $(\mathrm{kJ} / \mathrm{mol})$ \\
\hline$\beta$ & $20.8 \pm 2$ & $2.2 \times 10^{8}$ & 29.7 \\
MWS & $113 \pm 3$ & $6.0 \times 10^{17}$ & \\
\hline
\end{tabular}

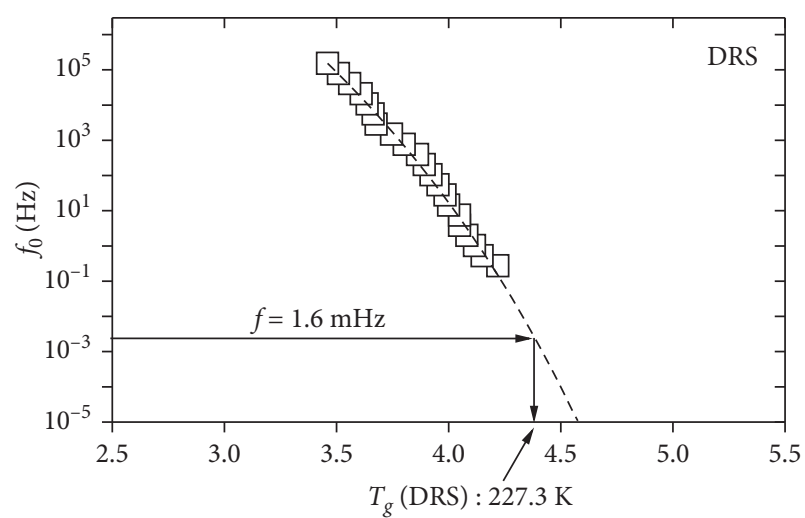

(a)

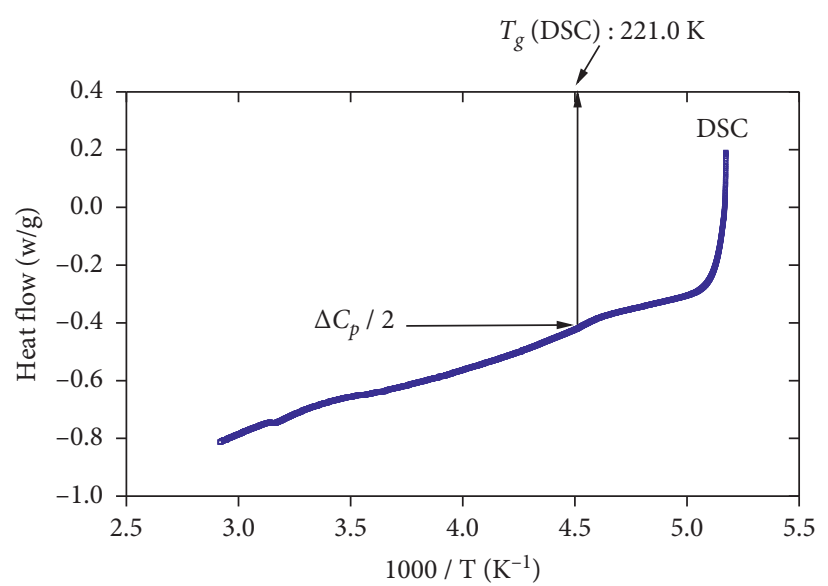

(b)

FIGURE 15: (a) the glass transition temperature determined by DRS and (b) the glass transition temperature determined by DSC.

TABLE 8: The dipole moment calculated for a specific monomer in EPDM.

\begin{tabular}{lccc}
\hline Type of relaxation & $T(\mathrm{~K})$ & $\mu_{\text {ons }}(D)$ & $\mu$ in prior result [49] $(D)$ \\
\hline$\beta$ (propylene) & 298 & 5.3 & 0.054 \\
\hline
\end{tabular}

decreased. The temperature behaviors of $\Delta \varepsilon$ are a general trend for $\alpha$ - and $\beta$-relaxations. As the temperature increased from $233 \mathrm{~K}$, the two $\alpha$ - and $\beta$-peaks separated in the temperature range from $233 \mathrm{~K}$ to $290 \mathrm{~K}$ and merged from $290 \mathrm{~K}$ to $373 \mathrm{~K}$, as shown in Figure 14. The two arrows in Figure 14 indicate the temperature at which the merge occurred. The intersection at $290 \mathrm{~K}$ in $\Delta \varepsilon$ and $f_{0}$ comes from the coexistence of two $\alpha$ - and $\beta$-processes with the same relaxation time. This is the first observation in polymers. Additionally, because the EPDM contains the flexibly attached dipolar side groups (methyl group $\left[-\mathrm{CH}_{3}\right]$ ), the value of $\Delta \varepsilon$ of the $\beta$-relaxation was smaller than that of $\alpha$-relaxation at low temperature $[47,48]$.

The activation energies for $\beta$ and MWS dielectric relaxation phenomena were also determined by the Arrhenius temperature dependence of equation (3). The activation energies of $\beta$ and MWS were 17.7 and $113 \mathrm{~kJ} / \mathrm{mol}$, respectively.

The fitting results are summarized in Table 7. The activation energy of $\beta$-relaxation related to the orientational motion of the methyl group was compared with prior results [39].

The relaxation rate of $\alpha$-relaxation with the nonArrhenius temperature dependence could be described by the VFTH temperature dependence model of equation (4). $T_{g}$ could also be obtained from the temperature dependence of the imaginary permittivity measured at different frequencies. The determined $T_{g}$ is shown in Figure 15. This was compared with $T_{g}$ (DSC) determined by the DSC measurement (Figure 15(b)). The $T_{g}$ (DRS) for the dielectric measurement result was found to be 227.3 K $( \pm 4.3) . T_{g}$ (DSC) determined by DSC measurements was found to be $221.0 \mathrm{~K}$. The difference in $T_{g}$ between the two methods is relatively large, which may be related to the heating rate of the two methods. The reason for the inconsistency is under investigation.

Similar to NBR, the dipole moment for each monomer in EPDM could be calculated from the dielectric measurement data. The dipole moment calculated according to the theory of Onsager is shown in Table 8, together with that obtained from prior results [49]. The large difference between the two calculations may be due to the merging process at $298 \mathrm{~K}$, which could cause an increase in the uncertainty in the deconvolution of the dielectric spectrum. And, in the reference data, Work et al. [49] has approached a traditional calculation of the electrical dipole moment of a microscopic system. However, our calculation was applied to macroscopically explain the local electric field effect in an isotropic dipolar system. Thus, the above critical reason may cause the difference between two calculations.

For legible visualization of the relaxation rate of every dielectric relaxation spectrum, the positions of the relaxation 

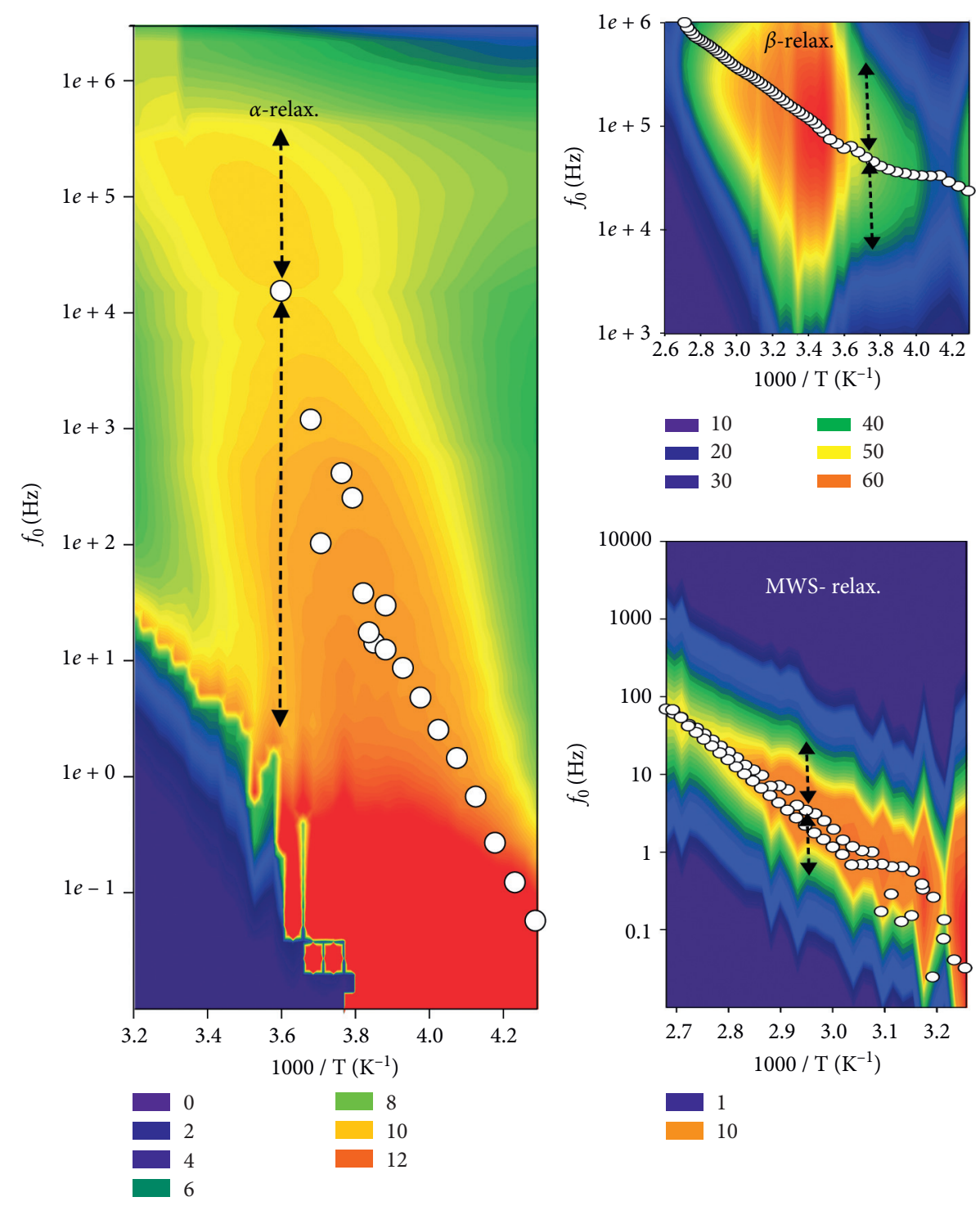

FIGURE 16: Relaxation rate and contour plot of the dielectric relaxation phenomena for EPDM. The overlapped circle symbols of MWS and $\alpha$-relaxation just denote the repeated analysis.

peak versus reciprocal temperature are mapped in Figure 16. The $2 \mathrm{D}$ contour mapping of imaginary permittivity can be verified by the relaxation morphology. The width for the dielectric relaxation peak of $\beta$ and MWS is symmetric on the basis of the top for the relaxation peak in the frequency domain. However, the width of the dielectric relaxation peak of $\alpha$ is asymmetric.

\section{Conclusion}

The dielectric spectra are mainly dependent on relaxation times for primary and secondary relaxation processes with conductivity contribution. In addition, they are broadened by a wider distribution or superimposed relaxation processes. Thus, it is not easy to determine the corresponding relaxation processes embedded in a polymer and elucidate the origin of the mechanism. To overcome this problem, we have developed a computer simulation program "dispersion analyzer" by employing a modified numerical method of nonlinear optimization.

With the help of the developed simulation program, we could perform a molecular dynamics study of synthetic rubber polymers. The authentication, i.e., the monomers in synthetic polymers, could be defined by the dielectric relaxation response. The results were plainly designated using a monomer schematic. We calculated the activation energy of each monomer for the synthetic polymer using the Arrhenius temperature dependence model, and the glass transition temperature was calculated by the VFTH temperature dependence model; these results were similar to the DSC measurement results. Finally, we defined the electronic-permanent dipole moment for each side group in the polymer, and there has been no prior DRS study about these polymers.

In future research, we will supplement the additional functions in the program simulation, such as the constraint 
of the temperature dependency behavior of relaxations and the three-dimensional contour plot. The study of molecular dynamics for conductivity mechanisms at high temperatures and for secondary relaxation processes at low temperatures is in progress.

\section{Data Availability}

The data used to support the findings of this study are available from the corresponding author upon request.

\section{Disclosure}

Young Il Moon's present address is Department of Electronic and Electrical Engineering, Pohang University of Science and Technology (POSTECH), 77 Cheongam-ro, Pohang 790-784, Republic of Korea.

\section{Conflicts of Interest}

The authors have no conflicts of interest to declare.

\section{Acknowledgments}

This research was supported by the Development of Reliability Measurement Technology for Hydrogen Fueling Station funded by the Korea Research Institute of Standards and Science (KRISS-2020-GP2020-0007).

\section{References}

[1] H. Fujiwara, "Analysis of acrylonitrile butadiene rubber (NBR) expanded with penetrated hydrogen due to highpressure hydrogen exposure," Nippon Gomu Kyokaishi, vol. 89 , no. 10, pp. 295-301, 2016.

[2] R. A. Orza, P. C. M. M. Magusin, V. M. Litvinov, M. Van Duin, and M. A. J. Michels, "Mechanism for peroxide cross-linking of EPDM rubber from MAS13C NMR spectroscopy," Macromolecules, vol. 42, no. 22, pp. 8914-8924, 2009.

[3] C. H. Lee, J.-K. Jung, S. K. Jeon, K. S. Ryu, and U. B. Baek, "Nuclear magnetic resonance study of o-ring polymer exposed to high-pressure hydrogen," Journal of Magnetics, vol. 22, no. 3, pp. 478-482, 2017.

[4] X. Ge, M.-C. Li, and U. R. Cho, "Fabrication of EPDM rubber/ organo-bentonite composites: influence of hydrochloric acid on the characteristics of modified bentonite and final products," Polymer Korea, vol. 38, no. 1, pp. 62-68, 2014.

[5] T. Kawashima and T. Ogawa, "Prediction of the lifetime of nitrile-butadiene rubber by FT-IR," Analytical Sciences, vol. 21, no. 12, pp. 1475-1478, 2005.

[6] G. C. Psarras, G. A. Sofos, A. Vradis et al., "HNBR and its MWCNT reinforced nanocomposites: crystalline morphology and electrical response," European Polymer Journal, vol. 54, pp. 190-199, 2014.

[7] F. Zhang, Q. Zhao, T. Liu, Y. Lei, and C. Chen, "Preparation and relaxation dynamics of ethylene-propylene-diene rubber/ clay nanocomposites with crosslinking interfacial design," Journal of Applied Polymer Science, vol. 135, no. 1, Article ID 45553, 2018.

[8] D. Xu, V. Sridhar, S. P. Mahapatra, and J. K. Kim, "Dielectric properties of exfoliated graphite reinforced flouroelastomer composites," Journal of Applied Polymer Science, vol. 111, no. 3, pp. 1358-1368, 2009.

[9] M. Samet, V. Levchenko, G. Boiteux, G. Seytre, A. Kallel, and A. Serghei, "Electrode polarization vs. maxwell-wagner-sillars interfacial polarization in dielectric spectra of materials: characteristic frequencies and scaling laws," The Journal of Chemical Physics, vol. 142, no. 19, p. 194703, 2015.

[10] C. V. Channel and J. Jog, "Dielectric relaxations in PVDF/ $\mathrm{BaTiO}_{3}$ nanocomposites," Express Polymer Letters, vol. 2, no. 4, pp. 294-301, 2008.

[11] H. Lu, Z. Xy, and H. Zhang, "Influence of the relaxation of maxwell-wagner-sillars polarization and dc conductivity on the dielectric behaviors of nylon 1010," Journal of Applied Physics, vol. 100, no. 5, Article ID 054104, 2006.

[12] S. Cerveny, R. Bergman, G. A. Schwartz, and P. Jacobsson, "Dielectric $\alpha$ - and $\beta$-relaxations in uncured styrene butadiene rubber," Macromolecules, vol. 35, no. 11, pp. 4337-4342, 2002.

[13] S. S. N. Murthy, J. Sobhanadri, and J. Gangasharan, "The origin of $\beta$ relaxation in organic glasses," The Journal of Chemical Physics, vol. 100, no. 6, pp. 4601-4606, 1994.

[14] F. Kremer and A. Schönhals, Broadband Dielectric Spectroscopy, Springer, Berlin, Germany, 2003.

[15] A. Vassilikou-Dova and M. Kalogeras, "Dielectric analysis (DEA)," in Thermal Analysis of Polymers, Fundamentals and Applications, J. D. Menczel and R. B. Prime, Eds., pp. 497-614, Wiley, Hoboken, NJ, USA, 2009.

[16] J. P. Runt and J. J. Fitzgerald, Dielectric Spectroscopy of Polymeric Materials Fundamentals and Applications, American Chemical Society, Washington, DC, USA, 1997.

[17] J.-F. Chailan, G. Boiteux, J. Chauchard, B. Pinel, and G. Seytre, "Viscoelastic and dielectric study of thermally aged ethylenepropylene diene monomer (EPDM) compounds," Polymer Degradation and Stability, vol. 47, no. 3, pp. 397-403, 1995.

[18] G. Ajroldi, M. Pianca, M. Fumagalli, and G. Moggi, "Fluoroelastomers-dependence of relaxation phenomena on composition," Polymer, vol. 30, no. 12, pp. 2180-2187, 1989.

[19] N. Celette, I. Stevenson, L. David, J. Davenas, G. Vigier, and G. Seytre, "Irradiation effects on the relaxation behaviour of EPDM elastomers," Polymer International, vol. 53, no. 5, pp. $495-505,2004$.

[20] J. Pietrasik, M. Gaca, M. Zaborski, L. Okrasa, G. Boiteux, and O. Gain, "Studies of molecular dynamics of carboxylated acrylonitrile-butadiene rubber composites containing in situ synthesized silica particles," European Polymer Journal, vol. 45, no. 12, pp. 3317-3325, 2009.

[21] Bio logics, https://www.bio-logic.net/products/multichannelconductivity/vsp-300-6-channels-electrochemical-workstation/.

[22] CSA Group, Test Methods for Evaluating Material Compatibility in a Compressed Hydrogen Applications-Polymers, CSA Group, Toronto, Canada, 2019.

[23] TA instruments, https://www.tainstruments.com/q600/.

[24] C. Grosse, "A program for the fitting of debye, cole-cole, coledavidson, and havriliak-negami dispersions to dielectric data," Journal of Colloid and Interface Science, vol. 419, pp. 102-106, 2014.

[25] N. Karan, D. Pradhan, R. Thomas, B. Natesan, and R. Katiyar, "Solid polymer electrolytes based on polyethylene oxide and lithium trifluoro- methane sulfonate $\left(\mathrm{PEO}-\mathrm{LiCF}_{3} \mathrm{SO}_{3}\right)$ : ionic conductivity and dielectric relaxation," Solid State Ionics, vol. 179, no. 19-20, pp. 689-696, 2008.

[26] T. T. N. Dang, S. P. Mahapatra, V. Sridhar, J. K. Kim, K.-J. Kim, and H. Kwak, "Dielectric properties of nanotube reinforced butyl elastomer composites," Journal of Applied Polymer Science, vol. 113, no. 3, pp. 1690-1700, 2009. 
[27] S. A. Mansour, M. E. Al-ghoury, E. Shalaan, M. H. I. El Eraki, and E. M. Abdel-Bary, "Dielectric dispersion and AC conductivity of acrylonitrile butadiene rubber-poly (vinyl chloride)/graphite composite," Journal of Applied Polymer Science, vol. 122, no. 2, pp. 1226-1235, 2011.

[28] C. Gerstl, G. J. Schneider, W. Pyckhout-Hintzen et al., "Segmental and normal mode relaxation of poly (alkylene oxide)s studied by dielectric spectroscopy and rheology," Macromolecules, vol. 43, no. 11, pp. 4968-4977, 2010.

[29] W. H. Stockmayer, "Dielectric dispersion in solutions of flexible polymers," Pure and Applied Chemistry, vol. 15, no. 34, pp. 539-554, 1967.

[30] C. M. Roland and C. A. Bero, "Normal mode relaxation in linear and branched polyisoprene," Macromolecules, vol. 29, no. 23, pp. 7521-7526, 1996.

[31] B. Kuttich, C. Lederle, and B. Stühn, "Water dependence of the dielectric $\beta$-relaxation in poly ( $\varepsilon$-caprolactone)," The Journal of Chemical Physics, vol. 139, no. 24, p. 244907, 2013.

[32] R. D. Priestley, L. J. Broadbelt, J. M. Torkelson, and K. Fukao, "Glass transition and $\alpha$-relaxation dynamics of thin films of labeled polystyrene," Physical Review E, vol. 75, no. 6, 2007.

[33] P. Pissis and D. Fragiadakis, "Dielectric studies of segmental dynamics in epoxy nanocomposites," Journal of Macromolecular Science, Part B, vol. 46, no. 1, pp. 119-136, 2007.

[34] A. M. Dunn, O. S. Hofmann, B. Waters, and E. Witchel, "Cloaking malware with the trusted platform module," in Proceedings of the 20th USENIX Security Symposium, pp. 395-410, San Francisco, CA, USA, August 2011.

[35] K. Kyriakos, K. N. Raftopoulos, P. Pissis et al., "Dielectric and thermal studies of the segmental dynamics of poly (methyl methacrylate)/silica nanocomposites prepared by the sol-gel method," Journal of Applied Polymer Science, vol. 128, no. 6, pp. 3771-3781, 2013.

[36] M. Wübbenhorst, E. M. Van Koten, J. C. Jansen, W. Mijs, and J. Van Turnhout, "Dielectric relaxation spectroscopy of amorphous and liquid-crystalline side-chain polycarbonates," Macromolecular Rapid Communications, vol. 18, no. 2, pp. 139-147, 1997.

[37] B. Atawa, N. T. Correia, N. Couvrat et al., "Molecular mobility of amorphous $n$-acetyl- $\alpha$-methylbenzylamine and debye relaxation evidenced by dielectric relaxation spectroscopy and molecular dynamics simulations," Physical Chemistry Chemical Physics, vol. 21, no. 2, pp. 702-717, 2019.

[38] S. U. Vallerien, F. Kremer, and C. Boeffel, "Broadband dielectric spectroscopy on side group liquid crystal polymers," Liquid Crystals, vol. 4, no. 1, pp. 79-86, 1989.

[39] R. Korus and K. F. O'Driscoll, Polymer Handbook, Wiley, Hoboken, NJ, USA, 2nd edition, 1975.

[40] L. Hoffmann, J. Beerwerth, D. Greim et al., "Reorientational dynamics of trimethoxyboroxine: a molecular glass former studied by dielectric spectroscopy and $11 \mathrm{~B}$ nuclear magnetic resonance," The Journal of Chemical Physics, vol. 152, no. 3, Article ID 034503, 2020.

[41] H. Kothandaraman, D. Sangeetha, A. A. Sriramulu, M. P. M. Nayagam, and T. M. Aminabhavi, "Polymerization kinetics of styrene using coordination catalysts containing rare earth compounds," Journal of Applied Polymer Science, vol. 80, no. 7, pp. 1071-1084, 2001.

[42] D. Fragiadakis, P. Pissis, and L. Bokobza, "Glass transition and molecular dynamics in poly (dimethylsiloxane)/silica nanocomposites," Polymer, vol. 46, no. 16, pp. 6001-6008, 2005.

[43] G. Polizos, E. Tuncer, A. L. Agapov et al., "Effect of polymernanoparticle interactions on the glass transition dynamics and the conductivity mechanism in polyurethane titanium dioxide nanocomposites," Polymer, vol. 53, no. 2, pp. 595-603, 2012.

[44] Zbigniew Kisiel, Improved Dipole Moments for Acrylonitrile and Propionitrile, Polish Academy of Sciences, Warsaw, Poland, 2011, https://kbosuedu/handle/1811/49681.

[45] D. O’Neill, R. M. Bowman, and J. M. Gregg, "Dielectric enhancement and maxwell-wagner effects in ferroelectric superlattice structures," Applied Physics Letters, vol. 77, no. 10, pp. 1520-1522, 2000.

[46] T. Wang, J. Hu, H. Yang et al., "Dielectric relaxation and maxwell-wagner interface polarization in $\mathrm{Nb}_{2} \mathrm{O}_{5}$ doped $0.65 \mathrm{BiFeO}_{3}-0.35 \mathrm{BaTiO}_{3}$ ceramics," Journal of Applied Physics, vol. 121, no. 8, 2017.

[47] G. Kremer and A. Bouhaili, "Modèles monétaristes de l'hyperinflation," Tiers-Monde, vol. 33, no. 129, 1992.

[48] G. Williams and D. C. Watts, "Molecular motion in solid amorphous polymers. The dielectric relaxation of a polynonyl methacrylate and poly-n-lauryl methacrylate as a function of frequency, temperature and applied pressure," Transactions of the Faraday Society, vol. 67, p. 2793, 1971.

[49] R. N. Work, R. D. McCammon, and R. G. Saba, "Effective dipole moment of polypropylene," The Journal of Chemical Physics, vol. 41, no. 9, pp. 2950-2951, 1964. 